\title{
Erratum
}

\section{Nutrient flows in suckler farm systems under two levels of intensity}

\section{Jürgen Schellberg, Lellmann Arno and Kühbauch Walter}

Institute of Crop Science and Resource Conservation, University of Bonn, D 53115 Bonn, Katzenburgweg 5 , Germany; e-mail: j.schellberg@uni-bonn.de

Nutrient Cycling in Agroecosystems (2006) 74:41-57

DOI 10.1007/s10705-005-5770-6

\section{Publisher's Note}

Due to error by the publisher the article was published without incorporating the author's corrections. Springer would like to apologise to the authors, Jürgen Schellberg, Lellmann Arno and Kühbauch Walter 